\title{
NiETZSCHE, FOUCAUlT E A TEORIA CRÍTICA: ELEMENTOS PRELIMINARES PARA UM DEBATE ${ }^{1}$
}

Ernani Chaves (UFPA) ${ }^{2}$

erna.nic@hotmail.com

Resumo: Na chamada primeira geração da Teoria Crítica, a de Adorno e Horkheimer, Nietzsche, ao lado de Marx e Freud foi um interlocutor privilegiado. A crítica de Habermas, nome central da segunda geração, separou Nietzsche da Teoria Crítica, ou melhor, atribuiu a Nietzsche parte dos problemas da crítica que a primeira geração dirigiu à razão. Já a terceira geração, da qual Axel Honneth é o nome mais conhecido, volta a problematizar a relação entre Teoria Crítica e Nietzsche, por meio do pensamento de Michel Foucault. Esse artigo visa mostrar alguns aspectos dessa retomada, na qual os nomes de Nietzsche - como um dos precursores - e Foucault - como um continuador - são incluídos no horizonte da Teoria Crítica.

Palavras-chave: Teoria Crítica; razão; poder; sujeito.

Em diversas ocasiões, em especial nas entrevistas, quando instado a falar de seu percurso filosófico, Michel Foucault sempre destacou a importância de Nietzsche para a formulação de suas próprias questões e para a própria caracterização de seu modo de filosofar. Vejamos alguns exemplos: no

\footnotetext{
${ }^{1}$ Recebido: 18-09-2016/ Aceito: 26-12-2016/ Publicado on-line: 19-01-2017.

${ }^{2}$ Ernani Chaves é Bolsista de Produtividade em Pesquisa do CNPq - Nivel 1C e Professor Titular da Universidade Federal do Pará, Belem, PA, Brasil.
} 
"Prefácio" de 1961 à primeira edição da História da Loucura, incluía sua pesquisa "sob o sol da grande pesquisa nietzschiana" (FOUCAULT 1994a, p. 162); comentando As palavras e as coisas, em uma entrevista de 1966, a propósito da relação entre o classicismo alemão, a literatura alemã e as exigências da modernidade, dizia que tal relação não apenas explicaria a permanente confrontação de Nietzsche com o antigo e o moderno, mas também que, "agora, é ele que nos serve de luz" (FOUCAULT 1994b, p. 502); por ocasião do anúncio do início dos trabalhos de publicação da edição Colli-Montinari das obras de Nietzsche na França, em uma entrevista conjunta com Gilles Deleuze, também em 1966, Nietzsche é considerado uma "cesura na história do pensamento ocidental", pois com ele "o modo do discurso filosófico mudou", ao tornar incompatível para sua filosofia o "eu" cartesiano, "supera todo o pensamento ocidental contemporâneo" (FOUCAULT 1994c, p. 551); em 1967, por sua vez, o caráter da filosofia de Nietzsche é definido como sendo o de um "diagnóstico" e não mais, como o fizera a tradição, "de procurar dizer uma verdade que possa valer para todos e para todos os tempos" (FOUCAULT 1994d, p. 606), observação que repetirá em outra entrevista deste mesmo ano (FOUCAULT 1994e, p. 612-13); em 1975, já no interior das discussões sobre Vigiar e punir, afirma que um "bom título" geral para o que ele próprio faz, seria "genealogia da moral", assinalando, nessa mesma entrevista, mais uma vez, a modificação introduzida por Nietzsche no discurso filosófico, ao acrescentar ao discurso filosófico a questão das "relações de poder": "Nietzsche é o filósofo do poder, mas que chegou a pensar o poder sem enclausura-lo no interior de uma teoria política" (FOUCAULT 1994f p. 
753; 1979, p. 233); em 1978, retoma a ideia de que Nietzsche "foi o primeiro, creio, que definiu a filosofia como sendo a atividade que serve para saber o que se passa e o que é que se passa agora", o papel do filósofo é o de "diagnosticar essas forças [que atuam no presente, EC], de diagnosticar a atualidade" (FOUCAULT 1994g, p. 573); alguns anos depois, em 1984, no "Prefácio" à edição inglesa do primeiro volume da História da sexualidade, dirá que deve à leitura de Nietzsche, "no começo dos anos 50", o acesso a um tipo de questão, que rompia "com a dupla tradição da fenomenologia e do marxismo" (FOUCAULT 1994h, p. 581).

Por outro lado, em algumas entrevistas a partir do final dos anos 1970 até a sua morte, Foucault refez o seu percurso filosófico, construindo uma espécie de autobiografia intelectual, na qual a referência a Nietzsche é sempre importante e decisiva. Em fins de 1978, numa entrevista que só será publicada em 1980, ele dirá que a descoberta de Nietzsche se deu "fora da universidade", uma vez que este, por sua utilização pelos nazistas, tinha sido excluído do ensino, enfatizando, por sua vez, seu encontro com Bataille, por meio de quem a relação entre Nietzsche, o marxismo e o comunismo, pode deixar de ser impossível (FOUCAULT 1994i, p.50). Mais ainda: seu encontro com Nietzsche tornou possível não apenas "fazer uma história da racionalidade, mas também a própria história da verdade", uma vez que para Nietzsche,

uma racionalidade - seja aquela de uma ciência, de uma prática, de um discurso - não se mede pela verdade que esta ciência, este discurso, esta prática possam produzir. A própria verdade faz parte da história do discurso e é como um efeito interno a um discurso ou a uma prática (FOUCAULT 1994i, p. 54). 
Em outra entrevista, quase dez anos depois da publicação do Vigiar e punir, dirá o seguinte, questionando a ênfase que se dava à busca dos "fundamentos da punição":

Sobre este ponto, é preciso ser ao mesmo tempo modesto e radical, radicalmente modesto, e relembrar o que Nietzsche disse há, agora, mais de um século, a saber, que nossas sociedades contemporâneas não sabem mais o que se faz quando se pune e o que se pune, no fundo, em princípio [não sabem mais] justificar a punição; tudo se passa como se praticássemos uma punição deixando valer, sedimentados um pouco, uns pelos outros, um certo número de ideias heterogêneas, que advém de histórias diferentes, de momentos distintos, de racionalidades divergentes (FOUCAULT 1994k, p. 641).

Naquela que talvez seja a mais importante e interessante entrevista, na qual Foucault refaz seu itinerário intelectual, concedida ao germanista francês Gérard Raulet, publicada na primavera de 1983, ele situará seu interesse por Nietzsche no interior do debate filosófico propriamente francês do pós-guerra, dominado pela fenomenologia e pelo marxismo, por Sartre e Marleau-Ponty. Mas também, pela antropologia de Levy-Strauss e pela psicanálise lacaniana (FOUCAULT 1994l, p. 434):

Para mim o problema se coloca um pouco, nos termos análogos aos que evoquei a pouco: será que um sujeito do tipo fenomenológico, transhistórico, é capaz de dar conta da historicidade da razão? Eis aí onde a leitura de Nietzsche foi para mim a fratura: há uma história do sujeito assim como uma história da razão, e a esta, à história da razão, não se deve perguntar por sua remissão a um ato fundador e primeiro do sujeito racionalista (FOUCAULT 19941, p. 436).

Além das palavras do próprio Foucault, é possível também recorrer aos testemunhos dos amigos e dos interlocutores filosóficos. Maurice Pinguet, por exemplo, que acompanhou Foucault nas férias do verão de 1953, na Itá- 
lia, diz o seguinte: "vejo Michel Foucault lendo, ao sol, na praia de Civitavecchia, as Considerações Extemporâneas" (ERIBON 1991, p.72). Paul Veyne, por sua vez, referindo-se ao contexto do último curso de Foucault no Collège de France, "A coragem da verdade", nos fala de uma confidência de Foucault: "Nietzsche, disse-me ele certa vez, não foi nenhum filósofo da verdade, mas do Wahr-Sagen ["dizer verdadeiro"]" (HONNETH \& SAAR 2003b, p.37).

A relação entre Foucault e Nietzsche já foi objeto de inúmeras pesquisas, discussões e debates, tanto no Brasil quanto no exterior. É importante observar que esses inúmeros trabalhos destacam esta ou aquela dimensão do problema, referem-se a estes ou aqueles textos, delimitam esta ou aquela questão específica. Toda essa discussão, entretanto, traz sempre consigo o problema do estado de publicação dos textos de Foucault. Ora, a partir de 1994, com a publicação dos quatro volumes dos Dits et écrits pela editora Gallimard e de 1999, quando se inicia a publicação dos cursos proferidos no Collège de France, a obra de Foucault não para de crescer. Em 2011, por exemplo, foi publicado o primeiro curso no Collège de France, que se intitula "A vontade de saber", no qual Foucault pretendia estabelecer uma oposição entre duas espécies de paradigmas no pensamento ocidental acerca dessa questão, o de Aristóteles e o de Nietzsche. A cada ano, descobrem-se novos textos, publica-se esta ou aquela conferência, proferidas tanto na França quanto fora dela. Se aludimos a essa situação, é porque certamente toda essa série de publicações altera, desloca, modifica, em aspectos fundamentais, a avaliação que se fez das relações entre Foucault e Nietzsche, desde o final da década de 1970 até a metade da década de 1990. 
$\mathrm{Na}$ história recente da recepção dessas relações, sem dúvida a posição ocupada por Jurgen Habermas foi fundamental. Pertencendo ao que se costumou chamar de "segunda geração" da Teoria Crítica ou ainda da Escola de Frankfurt, a Habermas deveu-se uma interpretação que culminava no descredenciamento crítico dos pensamentos de Nietzsche e Foucault. Com isso, Habermas demarcava seu afastamento em relação aos pais fundadores, ou seja, Adorno e Horkheimer. De fato, a primeira geração da Teoria Crítica, a qual acrescentaríamos ainda Marcuse e, em certa medida Walter Benjamin, tomou Nietzsche como um interlocutor importante. Para eles, não era possível pensar numa Teoria Crítica, em oposição à Teoria Tradicional (para retomarmos tanto a letra quanto o espírito do escrito programático de Horkheimer), sem uma permanente interlocução com Nietzsche. Uma interlocução que reunia Nietzsche a Freud e Marx, bem antes que a recepção francesa da década de 1960 realinhasse novamente esses três nomes. Não temos tempo aqui para nos demorarmos neste ponto, mas apenas gostaríamos de ressaltar que o debate iniciado por Habermas com seu libelo acusatório contra os "pósmodernos" em O discurso filosófico da modernidade (1985), encontrou enorme ressonância no Brasil e fortaleceu a crítica já existente aqui, aos pensamentos de Nietzsche e Foucault, considerados como "irracionalistas", "neoconservadores de direita", "inimigos do marxismo e da democracia" ou ainda, dentro dos círculos nietzschianos, fortaleceu a importância e a necessidade de criticar a leitura de Foucault e, assim, de algum modo, retirar o pensamento de Nietzsche de uma proximidade que lhe seria nefasta. Fora dos círculos nietzschianos era preciso, portanto, afastar $\mathrm{Ni}$ - 
etzsche e Foucault, ou seja, tudo o que era considerado "pós-moderno". Dentro dos círculos nietzschianos, por sua vez, era preciso afastar Nietzsche de Foucault e com isso resguardar Nietzsche de qualquer vinculação com os pósmodernos. É claro que esses debates foram necessários, importantes, pois essas posições são assumidas num determinado contexto histórico, no qual desempenharam um papel, que não pode ser desconhecido ou simplesmente descartado hoje.

Entretanto, a chamada terceira geração da Teoria Crítica, vai recolocar e renovar essas questões e esses problemas. $\mathrm{O}$ que se costuma chamar de terceira geração da Teoria Crítica, é o conjunto de pesquisadores, dentro e fora da Alemanha, que passaram a repensar essas questões a partir da tese de doutoramento de Axel Honneth, Foucault und die kritische Theorie, defendida em 1983 na Frei Universität, em Berlim, e publicada em 1985, com o título de Kritik der Macht. Reflexionenstufen einer sozial kristische Theorie. ${ }^{3}$ Entretanto, se este é o ponto de partida, o ponto culminante dessa renovação se dá com a realização, em 2001, de um Colóquio Foucault organizado por Axel Honneth e Martin Saar, em Frankfurt, destinado a fazer um "balanço" da recepção de Foucault e que pode ser considerado um divisor de águas, no que se refere às relações entre Nietzsche, Foucault e a Teoria Crítica. Os textos apresentados no Colóquio, reunindo pesquisadores alemães, franceses, ingleses e americanos, são o testemunho disso (HONNETH \& SAAR

\footnotetext{
${ }^{3}$ Em 1989, na série "Zur Einführung" ("Para Iniciantes"), da Editora Campus, Fink-Eitel já dizia, logo na sua "Introdução" ("Einleitung"), que a filosofia de Foucault, no seu conjunto, tinha um fundamento "nietzschiano", expresso da seguinte maneira: "A vontade de saber é uma vontade de poder” (p.7).
} 
2003b). Não por acaso, as primeiras linhas do "Prefácio", escrito pelos organizadores, já destacam a relação de Foucault com Nietzsche. Referindo-se à apresentação da edição francesa da edição Colli-Montinari das obras de Nietzsche, assinada por Deleuze e Foucault e à qual já me referi acima, eles destacam, justamente, a ideia de que "a obra de Nietzsche modifica o modus do discurso filosófico", que "Nietzsche multiplicou o gesto filosófico" ao "se interessar por tudo, por literatura, história, política, etc.", que ele "procurou, por todo canto, a filosofia" (IDEM, p. 9). Ora, essa dupla caracterização de Nietzsche, como aquele que, ao mesmo tempo, "modifica o modus do discurso filosófico" e o que "multiplica o gesto filosófico", Honneth e Saar atribuem ao próprio Foucault:

Isso vale, tanto para Nietzsche como para a obra de Foucault, que exerceu uma profunda e transformadora influência sobre o pensamento de nossa época, que persiste para além disso. Ao mesmo tempo, vale para Foucault, talvez mais ainda do que para Nietzsche, o fato de ele ter perseguido em uma multiplicidade e em uma abertura ilimitada das questões filosóficas, o rastro do pensamento, fora das questões filosóficas no seu sentido estrito (IDEM, IDEM).

No seu artigo, que abre a coletânea, Honneth, por sua vez, sem deixar de enfatizar os problemas que a obra de Foucault deixa em aberto e sem solução, mais uma vez associa Foucault a Nietzsche, mostrando que há em comum entre eles um mesmo gesto, como se ambos usassem a mesma "máscara de filósofos": "com Nietzsche - escreve Honneth - ele partilha, repetidamente, o subversivo gesto do começar de novo" (HONNETH \& SAAR 2003b, p.15). Com isso, Honneth quis acentuar, tanto em Nietzsche quanto em Foucault, os deslocamentos, as descontinuidades, as trans- 
formações, as repetidas reconstruções do próprio pensamento, seja para mostrar tanto o que há de comum, quanto o que mudou. Nesta perspectiva, poder-se-ia dizer que o espirito dos famosos "Prefácios" de 1886, que Nietzsche acrescentou à reedição de suas obras anteriores ao Zaratustra, ecoam, ressoam, nos "Prefácios" de Foucault as suas próprias obras, em especial naquele que foi escrito para o segundo volume da História da sexualidade, "O uso dos prazeres". Em ambos os gestos, as respectivas obras são relidas, reinterpretadas, até certo ponto revistas pelo próprio autor.

Dentro da questão mais ampla acerca das relações entre Nietzsche, Foucault e a Teoria Crítica, limitar-me-ei nesse artigo a apontar alguns aspectos da discussão a propósito do conceito de crítica, ou melhor dizendo, da genealogia como crítica.

Em primeiro lugar, lembramos que Raymond Geuss, no artigo publicado na coletânea de Honneth e Saar, (2003b, p. 145) chama atenção para o fato de que Foucault associa a ideia de crítica à de "problematização". Geuss vê nesta ligação, a presença de Nietzsche. Para tanto, ele cita um trecho do aforismo 276 d'A gaia ciência, não por acaso aquele que abre o Quarto Livro, no qual Nietzsche diz o seguinte, já na parte final do aforismo: "Que minha única negação seja desviar o olhar [...] quero ser algum dia, apenas alguém que diz Sim" (KSA, 3, p. 521). O "Ethos da Aufklärung" que Foucault vê impregnado em seu próprio trabalho significa, portanto, antes de mais nada, problematizar, colocar em questão todo e qualquer dado. Mas, seguindo Nietzsche, isso não quer dizer, de modo algum, "negar" simplesmente tudo e com isso encontrar-se no sentido mais comum de "crítica", ou seja, de crítica como 
negação do criticado. $\mathrm{O}$ "colocar tudo em questão" se contrapõe, é certo, ao programa kantiano da constituição de um domínio de competência e validade da razão pura, fundamentado na própria razão. Geuss, entretanto, considera a posição de Foucault não apenas derivada de uma espécie de programa nietzschiano, mas também devedora da noção de "epoché", advinda da fenomenologia de Husserl, com uma diferença essencial, uma vez que a "epoché" foucaultiana não se refere à uma investigação acerca do fundamento do conhecimento no interior do quadro de uma filosofia abstrata, que ainda acredita na existência de um "ego transcendental”, mas sim em conexão com um projeto de pesquisa historicamente definido, no interior do qual a palavra "histórico" também inclui o presente (HONNETH \& SAAR 2003b, p. 150). É como se Foucault tivesse sempre diante de si, a advertência que se encontra já no segundo aforismo do Primeiro Livro de Humano, demasiado humano, no qual Nietzsche denuncia a "falta de sentido histórico" como o "pecado hereditário de todos os filósofos" (KSA, 2, p. 24). Em outras palavras, na contramão de um sem número de leituras, Geuss afirma que a impossibilidade de ainda encontrarmos uma autofundamentação absoluta da razão, tal como Foucault - e antes dele, Nietzsche - procura mostrar, não implica em nenhum niilismo em relação à nossa "faculdade de conhecer". E se a teoria do discurso em Foucault entende que os jogos de linguagem relativos aos processos de justificação ("Rechtfertigungsprachspiele") são formações contingentes e diferentes, sujeitas aos processos históricos, isso não significa, decididamente, que eles não sejam justificáveis. Nessa perspectiva, poderíamos compreender melhor o Ethos da Aufklärung, próprio a Foucault, 
da seguinte maneira: 1) tal Ethos não prescreve o fechamento das fronteiras em relação às possibilidades do conhecimento, mas sim se refere à possibilidade de ultrapassálas; 2) se a arte, em especial a literatura, podem contribuir para o aprofundamento e o estabelecimento desse Ethos, a possibilidade de ultrapassar os limites, as fronteiras estabelecidas pelas posições de Kant e Husserl, isso implica necessariamente um elemento cognitivo, que Foucault chamou de "problematização". E, com isso, conclui Geuss, Foucault, na esteira de Nietzsche, introduz um terceiro tipo de crítica, uma crítica problematizadora, poderíamos dizer, no sentido de "colocação em questão" ("In-Frage Stellung”). Ora, nessa perspectiva, podemos compreender também o potencial crítico da genealogia como método, como a "dissolução histórica das identidades autônomas" (idem, p. 152). A genealogia como crítica não se situa, portanto, no sentido ordinário de crítica, como automática negação daquilo que é analisado. Também não está preocupada, diretamente, em encontrar a verdade ou a falsidade de algo. Não se trata, por exemplo, de saber se o pecador sentiu ou não um remorso equivalente à sua falta. Colocar esse tipo de questão seria ocultar o sentido crítico da genealogia. A pergunta correta, ao contrário, seria aquela pela validade da utilização universal dos conceitos de "remorso", "culpa/pecado", "punição", "igreja”, etc.: "quem são essas pessoas que por meio de um determinado desenvolvimento histórico, conseguem produzir e incorporar essas identidades?" (Idem, p. 153).

Nessa perspectiva, introduzo um outro interlocutor nessa questão, que é Pierre Hadot, o grande especialista em filosofia antiga. Hadot, cuja candidatura ao Collège de 
France fora apresentada pelo próprio Foucault nos permite também, por meio de sua própria interpretação de Nietzsche, entender um pouco a posição de Foucault, em especial nos seus últimos cursos e livros, nos quais Foucault tematiza, em muitos aspectos em clara ligação com Nietzsche, a ideia de que a ética grega é uma "estética da existência".

Em seu hoje clássico estudo, "A filosofia como maneira de viver", Hadot escreve: "Os historiadores da filosofia deram, em geral, muito pouca atenção ao fato de que a filosofia antiga é, antes de tudo, uma maneira de viver. Eles consideram sobretudo a filosofia como um discurso filosófico" (2002, p. 296). Hadot procura explicar o processo histórico que levou a essa desconsideração, mostrando, de início, o trabalho de correção do nexo entre teologia e filosofia empreendido no interior das universidades medievais, de tal modo que a filosofia se tornasse uma "atividade puramente teórica e abstrata", na medida em que os "exercícios espirituais" da filosofia antiga foram integrados à espiritualidade cristã, tal como os encontramos na famosa obra Exercícios espirituais, de Santo Inácio de Loiola. Para Hadot, a filosofia universitária excluiu do seu horizonte a compreensão do mais profundo significado da filosofia antiga. E na época moderna, segundo a periodização de Hadot, na "idade clássica", segundo a periodização de Foucault, as tentativas de renovação do potencial criador da filosofia se deram com filósofos que estiveram à margem da universidade, tais como Descartes, Spinoza, Malebranche, Leibniz. Este mesmo panorama encontramos no século XIX. Daí a importância da posição crítica de Schopenhauer e Nietzsche, ressalta Hadot, diante da instituição universitária: "Na filosofia universitária moderna, a filosofia não é 
mais, evidentemente, uma maneira de viver, um gênero de vida, a menos que ela seja o gênero de vida do professor universitário. Ela tem por elemento, por lugar vital, a instituição escolar do estado, aquilo que, de resto, sempre foi e pode permanecer uma ameaça para a independência da filosofia” (HADOT 2003a, p. 298). É possível entretanto também dizer que esses aspectos essenciais da filosofia antiga ainda puderam ressurgir, aqui e ali, no interior da filosofia moderna e que não desapareceram totalmente. Hadot nos lembra, por exemplo, que as Meditações de Descartes, trazem em seu próprio nome a noção de "exercício" e que a Ética se Spinoza, por sua vez, também se encontra, na sua forma sistemática e geométrica, em continuidade com o estoicismo. Mas, foram efetivamente as filosofias de Schopenhauer e Nietzsche, "convites para uma transformação radical da maneira de viver" (HADOT 2003a, p. 299). Entretanto, há uma profunda diferença entre a perspectiva que Hadot chama de "moderna", estendendo o arco de sua periodização de Descartes até os existencialistas franceses do século XX, e a filosofia antiga. Uma diferença, que as posições de Schopenhauer e Nietzsche confirmaram à exaustão. Nessa perspectiva, diz ele: "Poder-se-ia dizer que aquilo que diferencia a filosofia antiga da filosofia moderna é que na filosofia antiga não são apenas Crisipo ou Epicuro que são considerados como filósofos, na medida em que eles desenvolveram um discurso filosófico, mas também todo aquele que vive segundo os preceitos de Crisipo ou de Epicuro. Um político como Catão é considerado como um filósofo e mesmo como um sábio, embora ele não tenha escrito nada, nem ensinado nada, sua vida foi perfeitamente estóica [...] A filosofia antiga propõe ao homem uma arte de viver, a fi- 
losofia moderna, ao contrário, se apresenta antes de tudo como a construção de uma linguagem técnica reservada aos especialistas" (HADOT 2003a, p. 300).

Ora, poderíamos dizer que a posição de Hadot reforça, em Foucault, uma certeza, qual seja, a de que o potencial crítico da genealogia é inseparável da retomada de uma concepção de filosofia não-universitária, ou seja, não confinada ao comentário, à exegese dos textos, à reconstrução dos argumentos, à exposição das estruturas. Eu disse "não confinada". Ou seja, não se trata para Foucault, de retomar, em meio a nossa época, o modelo da filosofia antiga. O que seria, numa certa medida, absolutamente impossível. Não se trata de desqualificar, no seu todo, a filosofia universitária, mas de repensar sua função e seus limites. Foucault encontrava esse modelo, na figura de Jean Hypollyte, seu professor na Escola Normal Superior e que foi, como sabemos, um dos grandes especialistas em Hegel. Foucault escreveu dois textos em homenagem a Hypollyte. Um deles, que é um dos mais comentados textos na história na recepção de Nietzsche, o famoso "Nietzsche, a genealogia e a história”, publicado em 1971, mas cujas primeiras anotações remontam, no mínimo, a 1969. O outro, entretanto, menos conhecido e menos comentado, é o necrológio ao seu professor e mestre, publicado na revista Esprit, logo depois da morte de Hypollyte. Nesse texto, um belo texto, Foucault afirma que o ensino de Hypollyte ultrapassava as regras da tradição francesa do comentário e se dirigia para a região das problematizações. O comentário, o estudo rigoroso do texto e suas fontes - Foucault se refere, em especial, é claro, aos cursos de Hypollyte sobre Hegel - não basta, é preciso sair do espaço da exegese conceitual para o espaço 
do pensamento, isto é, das problematizações. Não por acaso, Foucault chamou sua cátedra no Collège de France, de "História dos sistemas de pensamento". Com isso, pretendo reler a célebre frase de Foucault no final de uma entrevista de 1975, sobre o Vigiar e Punir, na qual ele diz que quanto a Nietzsche, cansado de fazer comentários sobre ele, é preciso agora fazê-lo "ranger", "gritar", é preciso "deformá-lo". Esta afirmação, lida de maneira rápida e superficial, parece indicar que se pode, com Nietzsche, fazer qualquer coisa, sobre Nietzsche, dizer qualquer coisa. Penso, ao contrário, que essa frase indica algo inteiramente diverso: que continuar a crítica de Nietzsche, aprofundar o seu trabalho, não significa ser apenas um comentador de sua obra, mas é preciso retomar seus problemas e as questões que ele deixou em aberto. Tais como, paradoxalmente, seu mestre Hypollyte havia feito com Hegel. A "caixa de ferramentas" - a metáfora é de Deleuze numa conversa com Foucault, "Os intelectuais e o poder", de 1975 - portanto, não pode ser aberta com qualquer chave e nem manuseada de qualquer maneira. O "Ethos da Aufklärung" não permite que se chame um encanador quando se tem, em casa, problemas elétricos.

Esse momento de ruptura - pois visa reintegrar à tradição da Teoria Crítica, o que Habermas procurou afastar, isto é, um estilo e um modo de pensamento comuns a Nietzsche e a Foucault - se completa, em 2007, com a publicação da tese de doutorado de Martin Saar, intitulada Genealogie als Kritik. Geschichte und Theorie des Subjekts nach Nietzsche und Foucault ["Genealogia como crítica. História e teoria do sujeito segundo Nietzsche e Foucault"]. Já no primeiro parágrafo da "Introdução", Saar não deixa de apontar o lugar-comum das críticas a uma possível relação 
entre crítica e procedimento genealógico - "conclusões falsas do ponto de vista da análise das gêneses", "conclusões ilegítimas acerca da proveniência (Herkunft) do que tem e não tem valor" - para, ao contrário, "no contexto de muitas discussões históricas e no campo das ciências sociais, insinuar que uma pesquisa acerca das proveniências e origens possui uma função crítica”. Ele conclui seu argumento dizendo que seu livro tem como alvo "reconstruir as ideias e exigências de uma tal crítica histórico-genética, que procede genealogicamente para, sistematicamente, defende-la" (SAAR 2007, p.9). Analisando o que considera os elementos centrais do procedimento genealógico, as questões do sujeito, do poder e da forma (ou do estilo), a partir da Genealogia da moral, sem esquecer que esses três elementos já se encontram em outras obras, em especial em Além de bem e mal, o livro de Saar, assim como suas contribuições posteriores, o colocam no centro das discussões que levantei aqui, assim como de alguns problemas que lhes são inerentes.

Entretanto, cabe a Thomas Lemke uma espécie de primazia na renovação desse debate, pelo menos no interior da recepção alemã. Em 1977, foi publicada a sua tese de doutorado, Eine Kritik der politischen Vernunft. Foucaults Analyse der modernen Gouvernamentalität, defendida um ano antes na Faculdade de Ciências Sociais da Universidade de Frankfurt. Antes mesmo da publicação dos cursos de Foucault no Collège de France, Lemke ouviu as gravações dos cursos, disponíveis naquela época no Centre Michel Foucault, localizado na biblioteca dos Dominicanos, a Saulchoir, em Paris. Um dos impulsos centrais da obra de Lemke é justamente o estudo das "implicações políticas da teoria 
foucaultiana do poder" (LEMKE 2014, p.15), um debate no qual Nietzsche aparece diretamente implicado. Lemke se confronta com as diversas interpretações que o lugar de $\mathrm{Ni}$ etzsche suscitou nesse debate, desde a denúncia de um "relativismo monolítico", que "desmentia qualquer exigência de libertação" até as críticas mais conhecidas de Habermas e Honneth, acerca da importância de uma exigência normativa de validade universal, que teria sido desprezada por Foucault. Ora, mas é justamente em relação ao problema do uso que Foucault faz do procedimento genealógico, que a posição de Lemke no debate sobre a relação entre Foucault e Nietzsche aparece. Segundo ele, ao comentar "Nietzsche, a genealogia e a história", é necessário apontar um elemento muito importante e decisivo nesse texto e que repercutirá na obra posterior de Foucault, qual seja, de que ele formula, pela primeira vez, nos rastros de Nietzsche, a ideia de que é o corpo humano o objeto privilegiado das práticas de poder e, como tal, se torna, por consequência e paralelamente, o próprio objeto da genealogia (LEMKE 2014, p. 58, nota 17). Nessa perspectiva, Foucault entende o procedimento genealógico de uma maneira muito singular, que não diz respeito em primeiro e único lugar, a uma investigação teórica, própria à filosofia tradicional, mas muito mais próxima de um diagnóstico médico, "que se ocupa menos com os atos conscientes do que com os processos corporais, de tal modo que o genealogista se assemelha a um médico", cujo olhar "se volta para um diagnóstico, para dizer as diferenças" (idem).

Nessa perspectiva, Lemke analisa na quarta secção da primeira parte de seu livro, dedicada ao problema da "microfísica do poder", o que ele chama, retomando uma ex- 
pressão do próprio Foucault, da "hipótese Nietzsche" (Idem, p. 90). Trata-se, ao meu ver, de uma das mais interessantes análises da interpretação foucaultiana de Nietzsche, para mostrar o quanto essa "hipótese" possui uma vida intensa, porém curta, no interior do pensamento de Foucault sobre o poder e suas implicações políticas. Ou seja, uma "hipótese" levantada, que sustentava algumas posições, mas para em seguida, ser abandonada. No mínimo, esse tipo de interpretação nos acautela quanto à ligeireza com a qual muitas vezes se caracteriza Foucault como um "nietzschiano" inveterado, qualquer que seja o sentido que se atribui a essa qualificação.

Para finalizar, gostaria de afirmar que a interlocução da Teoria Crítica com Nietzsche, pela primeira geração, assim como com Nietzsche e Foucault, pela segunda e terceira geração dos teóricos críticos, constitui um dos capítulos mais importantes e mais interessantes da história da recepção de Nietzsche. E, como tal, merece uma atenção sempre cuidadosa e redobrada. Apresentei aqui alguns elementos que espero, tragam ao debate, uma outra perspectiva, em especial ao referenciar muito mais o debate alemão do que as interpretações francesas de Foucault, que inflacionam o debate brasileiro sobre o seu pensamento, seja do lado dos estudiosos de Foucault, seja do lado dos estudiosos de Nietzsche.

Abstract: During the so-called first generation of Critical Theory, that of Adorno and Horkheimer, Nietzsche, alongside Marx and Freud, was a privileged interlocutor. The critique of Habermas, a central name for the second generation, separated Nietzsche from Critical Theory, attributing him a decisive part of the critical problems that the first generation directed to reason. By its turn, the third generation, of which Axel Honneth is the famous name, once again problematizes the relations between Nietzsche and Critical 
Theory by the means of Michel Foucault's thoughts. This article intends to show some aspects of this rescue, on which the names of Nietzsche - as a precursor - and Foucault - as a continuer - are included in the horizon of Critical Theory.

Keywords: Critical Theory; reason; power; subject.

\section{REFERENNCIAS}

FINK-EITEL, Hinrich. Foucault, Hamburg: Junius Verlag, 1989.

FOUCAULT, Michel. "Préface". Vol.1. Dits et écrits, Paris: Gallimard, 1994a.

. "Michel Foucault, 'Les mots et les choses"”. Vol.1. Dits et écrits, Paris: Gallimard, 1994b.

. "Michel Foucault et Gilles Deleuze veulent rendre à Nietzsche son vrai visage". Vol.1. Dits et écrits, Paris: Gallimard, 1994c.

. "Qui êts-vous professuer Foucault?". Vol.1. Dits et écrits, Paris: Gallimard, 1994d.

" "Entretien sur la prision: le livre et as méthode". Vol.2. Dits et écrits, Paris: Gallimard, 1994e.

. "La scène de la philosophie". Vol.2. Dits et écrits, Paris: Gallimard, $1994 f$.

. "Prèface à l'Histoire de la sexualité". Vol.2. Dits et écrits, Paris: Gallimard, 1994g.

. "Entretien avec Michel Foucault". Vol.4. Dits et écrits, Paris: Gallimard, 1994h. 
. “Qu'appelle-t-on punir?”. Vol.4. Dits et écrits, Paris: Gallimard, $1994 \mathrm{i}$.

. "Structuralisme et poststructurslisme". Vol.4. Dits et écrits, Paris: Gallimard, 1994j.

HABERMAS, Jurgen. Der philosophische Diskurs der Moderne. Frankfurt: Suhrkamp, 1985.

HADOT, Pierre. Exercices Spirituels et Philosophie Antique. Paris: Éditions Albin Michel, 2003a.

HONNETH, A. und SAAR, M. (Hrsg.). Michel Foucault. Zwischenbilanz einer Rezeption. Frankfurter FoucaultKonferenz 2001. Frankfurt: Suhrkamp, 2003b.

LEMKE, Thomas. Eine Kritik der politischen Vernunft. Foucaults Analyse der modernen Gouvernamentalität, 2. Auflage, Hamburg: Argument Verlag, 2014.

NIETZSCHE, Friedrich. Kritische Studienausgabe. Frankfurt/München/Berlin: DTV/Walter de Gruyter, 1982.

SAAR, Martin. Genealogie als Kritik. Geschichte und Theorie des Subjekts nach Nietzsche und Foucault. Frankfurt/New York: Campus Verlag, 2007. 